\title{
Cutting-edge technology and nocturnal headaches in adolescent smart phone users in Chiang Mai, Thailand \\ A time series study
}

\author{
Wanna Chongchitpaisan, Phongtape Wiwatanadate, \\ Surat Tanprawate and Assawin Narkpongphun \\ Faculty of Medicine, Chiang Mai University, Chiang Mai, Thailand, and \\ Nipapon Siripon \\ Faculty of Engineering, Chiang Mai University, Chiang Mai, Thailand
}

\begin{abstract}
Purpose - Nocturnal headaches among adolescents were reported to be increased with the development of modern technology. The purpose of this paper is to investigate the smartphone electromagnetic radiation related to nocturnal headaches among high school students.

Design/methodology/approach - The time series study of all 12,969 records from 145 high school students Chiang Mai Province was selected from the population in the first phase by setting criteria. The samples completed a headache diary utilizing a smartphone application. The smartphone output power (SOP) was measured and recorded by the smartphone application and transmitted by e-mail to a researcher. The smartphone use, sleep quality, anxiety and depression also were assessed. Data were analyzed using Generalized Estimating Equation adjusting for demographic data, smartphone use, and sleep quality and otherwise.

Findings - The resulted showed the prevalence of repeated headaches to be 13.4 percent, nocturnal headache only 5.3 percent and the strongest effect of day time SOP at a $1.80-1.99 \times 10^{-5} \mathrm{~mW}$ range on nocturnal headaches $\left(\mathrm{OR}_{\text {adj }} 5.18 ; 95 \%\right.$ CI: 3.44-7.81). Meanwhile, Lag_6 of daily SOP exposure produced a nocturnal headache effect in a reverse dose-response manner. Furthermore, the nocturnal headache also had the strongest association with age, internet use and device brand $\left(\mathrm{OR}_{\mathrm{adj}} 2.33 ; 95 \%\right.$ CI: $1.08-5.05$, $\mathrm{OR}_{\mathrm{adj}} 2.14 ; 95 \%$ CI: $1.07-4.2$ and $\mathrm{OR}_{\text {adj }} 1.68 ; 95 \%$ CI: 1.1-2.4).

Originality/value - The electromagnetic radiation from a smartphone is the environmental variables influences on headache. The results suggested that there should be limited times for smartphone use and older age to start using a smartphone to prevent headache attacks at night.
\end{abstract}

Keywords Cutting-edge technology, Nocturnal headache, Smartphone output power, Thailand

Paper type Research paper

\section{Introduction}

Nocturnal headaches are headache symptoms that occur at night. A previous study found headaches at night were usually associated with sleep-disorders that were linked to a bidirectional way that shared some pathophysiological mechanisms $[1,2]$. The prevalence of

(C) Wanna Chongchitpaisan, Phongtape Wiwatanadate, Surat Tanprawate, Assawin Narkpongphun and Nipapon Siripon. Published in Journal of Health Research. Published by Emerald Publishing Limited. This article is published under the Creative Commons Attribution (CC BY 4.0) licence. Anyone may reproduce, distribute, translate and create derivative works of this article (for both commercial and non-commercial purposes), subject to full attribution to the original publication and authors. The full terms of this licence may be seen at http://creativecommons.org/licences/by/4.0/legalcode

The authors gratefully acknowledge the Faculty of Medicine, Chiang Mai University, for financial support for this study (Research Grant ID: COM-2558-05516), and also the teachers and students in Wattanothai Payap School for their engagement and help with the data collection required for this study.
Adolescent smart phone users

Received 23 January 2019 Revised 31 March 2019 Accepted 9 April 2019 
JHR

33,6

frequent nocturnal headaches at more than one per week ranged at around 8.4 percent in the general population[3]. Adolescents tend to have a delayed circadian preference and are "night owls." This change occurs in association with puberty; more physically mature adolescents have a preference for later bedtimes and may have a lower homeostatic sleep drive, consequently experiencing increased night time activities[4]. Furthermore, adolescents living in the digital age are in the group that ranks in the top three of the highest possession and use of smartphones in Thailand[5], with frequent usage at night.

Smartphones are modern mobile phones which have an electromagnetic emission source often held closest to the head and that can affect the human nervous system. Human nerves can be described as the electrical parts of human bodies and, as such, they are far from being in a state of equilibrium[6]. Previous studies found adolescents reporting that being awakened by a smartphone during the night at least once a month was associated with an increase in ill health symptoms such as headache and physical ill-being[7-9]. Furthermore, many of the recent pain-related studies reported activation by light[10] with results showing increases in cortical excitability during migraine attacks and visual hyper-excitability. The pain pathway begins with the intrinsic light cells that transform the light absorbed by the eye into a painful stimulus[11].

However, the effect of electromagnetic radiation from a smartphone on nocturnal headaches remains unclear. In addition, a previous study has shown that adolescents who attempted to reduce mobile phone during the day were more likely to stay up later at night using their mobile phones and being distracted by it[7]. This study attempts to assess the effect of smartphone electromagnetic radiation on nocturnal headache, the results of which will provide data for recommending safe smartphone use and reducing headaches.

\section{Materials and methods}

Study design and participants

This prospective time series study was conducted among high school students in Chiang Mai Province during October-December 2015. The samples were composed of grades 10-12 high school students who were selected from the first phase of study based on the set criteria. The inclusion criteria were that subjects should have no daily health-related behaviors, including liquor, coffee or tea consumption and smoking, have no disease or health problems diagnosed by doctors and should not be undergoing treatment.

\section{Data collection and headache measurement}

The students recorded data every day over a period of two to four months (60-120 days) in the daily questionnaires which were sent to the researcher from a smartphone application. The questions in the headache diary consisted of the time when a headache has begun and stopped, characteristics of pain and details of telephone conversations by the internet and hands-free or speakerphone use. The time cycle headache was classified by the time of headache in four time periods $(6 \mathrm{~h})$, morning time 6:01-12:00 a.m., daytime 12:01-18:00 p.m., evening time 18:01-24:00 p.m. and nocturnal time 0:00-6:00 a.m. The Pittsburg Sleep Quality Index, anxiety, depression and smartphone use were also assessed by diary questionnaires. The daily questionnaires were tested amongst 30 students in order to have reliable results by calculating internal consistency from Cronbach's $\alpha$, that is, 0.775 . The researcher trained the students about daily recording in a smartphone application through a three-day recording practice.

\section{The smartphone output power measurement}

The smartphone output power (SOP) was measured from the smartphone antenna and the application requested access to SOP via the program's framework by setting to save every $5 \mathrm{~min}$ 
and transmitting saved data by e-mail to the researcher every day. The mean of SOP was collected from the measurements taken at 5 -min intervals for $15 \mathrm{~min}$. The mean of daily dosage data was collected by applying the average time of exposure equation in the OET Bulletin 56 of the Federal Communications Commission ${ }^{12}$ as follows:

$$
\text { Daily Dose } \left.=\sum_{n=1}^{n}(\text { Average Output Power }) n x \text { (Duration Time }\right) n \text {, }
$$

where $n$ is the number of minutes measuring the average smartphone's output power. The duration is the time of measuring smartphone power each time. The study took measurements every $15 \mathrm{~min}$. The SOP was continuous data with non-normal distribution and divided into three groups of range.

\section{Statistical analysis}

The sample size was calculated based on a 10 percent prevalence of headaches by mobile phone use[12]. A total of 996 high school students made up the population for questionnaire interviews in the first phase of the study, and 200 students were selected by inclusion and exclusion criteria such as not being obese, having no daily health-related behaviors including liquor, coffee or tea consumption and smoking and having no disease or health problems diagnosed by doctors and undergoing treatment. To fill in the missing information, the researcher has extended the time for information collection from 60 to 120 days. In sum, 145 students completed data comprising 12,969 records which were coded and analyzed using Statistical Package for Social Science software version 20 to obtain the frequency, arithmetic mean and standard deviation. Relationships between SOP and nocturnal headaches, odds ratio (OR) and their 95\% confidence intervals $(95 \% \mathrm{CI})$ were investigated with $p$-value of $<0.05$ considered to be statistically significant. The Generalized Estimating Equation (GEE) was also run to control the confounding effects of such factors as demographic data, coffee or tea drinking, anxiety, depression, smartphone use and sleep quality. The GEE was used for data in the same cluster. In the analysis, therefore, the correlational structure was set and considered by the low score of Quasi-Likelihood under Independence Model Criterion. The Corrected Quasi-likelihood under Independence Model Criterion (QICC) has been used to compare the models under one correlational structure. A lower QICC score will correspond to a model of a better fit.

\section{Ethical considerations}

The study was approved by the Ethics Committee for Human Research, Faculty of Medicine at Chiang Mai University (COM 2558-03316). Informed consent was obtained from all participants.

\section{Results}

The 200 samples were asked to record headaches daily in a smartphone application. The SOP measured by another application was sent via a daily e-mail. Finally, 12,696 observations were obtained from a total of 145 students. The study found that the majority of the samples were female, 17.4 years old on average with a normal health condition. The headaches occurred in the morning, day time and in the evening accounting for 32.1, 30.2 and 32.4 percent of the participants, respectively, while only 5.3 percent reported a headache at night (Table I).

The data on SOP has been adjusted considering the value of error measured from each device brand to normalize the value for all device brands. The SOP values were aggregated into four time periods ( $6 \mathrm{~h}$ ), morning time 6.01-12.00 a.m., day time 12.01-18.00 p.m., evening time 18.01-24.00 p.m. and nocturnal time 0.01-6.00 a.m. The SOP values of each day were aggregated into a daily dose which was on average $2.08 \pm 16.2 \times 10^{-3} \mathrm{~mW}$ (Table II). 
JHR

33,6
Time cycles headache

Morning headache

Yes

No

Daytime headache

Yes

No

Evening headache

Yes

No

Table I.

Time cycles headache of participants presented as a percent
Nocturnal headache

Yes

No $n(\%)$

$547(32.1)$

1,158 (67.9)

$515(30.2)$

$1,190(69.8)$

$553(32.4)$

$1,152(67.6)$

$90(5.3)$

$1,615(94.7)$

\section{Table II.}

Smartphone output power (SOP) by time cycles and a daily dose of SOP

\begin{tabular}{lcllll}
\hline Variables & $n$ & Min. & \multicolumn{1}{c}{ Max. } & \multicolumn{1}{c}{ Mean } & SD \\
\hline Sum nocturnal dose & 12,696 & 0 & 1.54703000 & 0.0010027961 & 0.01452703607 \\
Sum morning dose & 12,696 & 0 & 0.60338196 & 0.0011027388 & 0.00644747700 \\
Sum daytime dose & 12,696 & 0 & 0.36942911 & 0.0011809051 & 0.00618567980 \\
Sum evening dose & 12,696 & 0 & 0.4080357 & 0.001072926 & 0.0065726714 \\
Daily dose & 12,696 & 0.00000009 & 1.54872780 & 0.0020833594 & 0.01623557023 \\
\hline
\end{tabular}

Apparently, the average SOP was the highest during day time, $1.18 \times 10^{-3} \mathrm{~mW}$, followed by morning time $1.1 \times 10^{-3} \mathrm{~mW}$, while the lowest is during night time, $1.0 \times 10^{-3} \mathrm{~mW}$. However, the maximum value of SOP occurred during night time at $1.55 \mathrm{~mW}$. The SOP value observations were then divided into three ranged groups: $\leqslant 1.79,1.8-1.99$ and $\geqslant 2.0 \times 10^{-5} \mathrm{~mW}$ (Table III). The SOP in the $1.8-1.99 \times 10^{-5} \mathrm{~mW}$ range appeared to be the least prevalent, with only 2.4 percent of the observations, taking place mostly during night time.

The researcher conducted a statistical test to evaluate the confounding effects and the relationship between various factors and found no interaction effect existed among them. Additional computation was made to adjust the effects of such potential confounders as demographic characteristics, and smartphone use. Autoregression 1 (AR1) was set as the correlational structure due to its lowest QIC (Table IV). The results revealed that younger aged users, internet use, and the brand of the device were associated with nocturnal headache $\left(\mathrm{OR}_{\text {adj }} 1.68 ; 95 \%\right.$ CI: 1.10-2.40, $\mathrm{OR}_{\mathrm{adj}} 2.14 ; 95 \%$ CI: 1.07-4.25 and $\mathrm{OR}_{\mathrm{adj}} 2.33$; 95\% CI: 1.08-5.05). Not using hands-free and internet use had a strong association with morning headache $\left(\mathrm{OR}_{\mathrm{adj}} 2.62 ; 95 \%\right.$ CI: $1.59-4.32$ and $\mathrm{OR}_{\text {adj }} 1.91 ; 95 \%$ CI: $\left.1.44-2.54\right)$, day time headache $\left(\mathrm{OR}_{\mathrm{adj}} 3.01\right.$; 95\% CI: 1.67-5.42 and $\mathrm{OR}_{\text {adj }} 1.88$; 95\% CI: 1.39-2.55) and evening headache ( $\mathrm{OR}_{\text {adj }} 3.02 ; 95 \% \mathrm{CI}$ : $1.67-5.49$ and $\mathrm{OR}_{\text {adj }} 2.62 ; 95 \% \mathrm{CI}$ : $\left.1.93-3.56\right)$. While the $\mathrm{OR}$ of nocturnal headache and lag were adjusted for all other factors using GEE, the exchangeable was set as the correlational structure

Table III.

Smartphone output power group by time cycles and daily dose

\begin{tabular}{|c|c|c|c|c|c|}
\hline Output power $\left(\times 10^{-5} \mathrm{~mW}\right)$ & Daily dose $n(\%)$ & Morning $n(\%)$ & Daytime $n(\%)$ & Evening $n(\%)$ & $\begin{array}{c}\text { Nocturnal } n \\
(\%)\end{array}$ \\
\hline$\leqslant 1.79$ & 1,943 (15.3) & 3,597 (31.4) & $2,479(20.1)$ & 2,303 (18.8) & 2,648 (20.9 \\
\hline $1.8-1.99$ & $186(1.5)$ & $226(2.0)$ & $120(1.0)$ & $79(0.6)$ & $301(2.4)$ \\
\hline$\geqslant 2.0$ & $10,567(83.2)$ & $7,646(66.7)$ & $9,710(78.9)$ & $9,896(80.6)$ & $9,747(76.8)$ \\
\hline
\end{tabular}


due to its lowest QIC (Table V). This study found daytime lag_2 of SOP in $1.80-1.99 \times 10^{-5} \mathrm{~mW}$ range to have a stronger association with nocturnal headache $\left(\mathrm{OR}_{\mathrm{adj}} 5.18 ; 95 \% \mathrm{CI}\right.$ : 3.44-7.81) compared to $\geqslant 2.00 \times 10^{-5} \mathrm{~mW}$. Meanwhile, lag_6 daily SOP had a relationship with nocturnal headache in the form of a reverse dose-response, while the SOP in $\leqslant 1.79 \times 10^{-5} \mathrm{~mW}$ range is related to daytime and evening headache $\left(\mathrm{OR}_{\mathrm{adj}} 1.52 ; 95 \% \mathrm{CI}: 1.10-2.11\right.$ and $\mathrm{OR}_{\mathrm{adj}} 2.60$; 95\% CI: 1.36-4.97). The relationship between morning headache and SOP $\left(\mathrm{OR}_{\mathrm{adj}} 194.11 ; 95 \% \mathrm{CI}\right.$ : 1.22-30821.27) will appear in the form of a dose-response.

\section{Discussion}

This study showed the prevalence of nocturnal headache to be only 5.3 percent, which was consistent with findings in Brazil in 2009, i.e. 8.4 percent[3]. The nocturnal headache in the present study is different from hypnic headache, as it does not wake one up from sleep, but it just occurs at night (00.01-6.00 a.m.).

The study showed that a young student compared to a student a year older was likely to face a relatively greater degree of nocturnal headache. This result was in contrast with most previous studies which found headache prevalence to vary positively with age[13]. The results from the present study are in line with those found from the first phase investigation on factors associated with a headache from mobile phone use that younger age groups had implications for mobile phone associated headache. Previous surveys revealed as high

\begin{tabular}{|c|c|c|c|c|c|c|c|}
\hline \multirow{2}{*}{ Factor } & \multicolumn{2}{|c|}{ Nocturnal headache } & \multirow[b]{2}{*}{ Crude OR } & \multirow[b]{2}{*}{ Adjusted OR } & \multicolumn{2}{|c|}{$95 \% \mathrm{CI}$} & \multirow[b]{2}{*}{$p$-value } \\
\hline & Yes & No & & & Lower & Upper & \\
\hline Age mean $\pm \mathrm{SD}$ & $16.9 \pm 0.8$ & $17.4 \pm 1.0$ & 1.76 & 1.68 & 1.1 & 2.4 & $<0.01$ \\
\hline $\begin{array}{l}\left(\times 10^{-3} \mathrm{~mW}\right) \\
\text { Mean } \pm \mathrm{SD} \\
\text { Total }\end{array}$ & $\begin{array}{c}0.8 \pm 1.7 \\
90\end{array}$ & $\begin{array}{c}2.1 \pm 16.0 \\
12,600\end{array}$ & $1.84 \times 10^{-35}$ & $1.03 \times 10^{-39}$ & $9.15 \times 10^{-74}$ & $1.17 \times 10^{-5}$ & 0.03 \\
\hline $\begin{array}{l}\text { Internet use } \\
\text { Yes/no }\end{array}$ & 1,416/11,280 & $1.5 / 0.6$ & 2.13 & 2.14 & 1.07 & 4.25 & 0.03 \\
\hline $\begin{array}{l}\text { Brand device } \\
\text { Other/Apple }\end{array}$ & $9,170 / 3,526$ & $0.8 / 0.4$ & 2.40 & 2.33 & 1.08 & 5.05 & 0.03 \\
\hline $\begin{array}{l}\text { Daytime dose } g r \\
1.80-1.99 / \geqslant 2.00\end{array}$ & $\begin{array}{l}\left(\times 10^{-5} \mathrm{~m}\right. \\
79 / 9,896\end{array}$ & $5.1 / 0.7$ & 6.97 & 5.18 & 3.44 & 7.81 & $<0.01$ \\
\hline
\end{tabular}

Note: Adjusted by age, BMI, vision, anxiety, depression, PSQI, internet use, hand free use, brand device and SOP

\section{Adolescent smart phone users}

Table IV. Odds ratios (OR) of nocturnal headache (24-6.00 a.m.) and their $95 \%$ confidence intervals for each factor and the daily dose adjusted for all other factors using GEE (AR1, $\mathrm{QIC}=899.92$, $\mathrm{QICC}=895.28$ )

\begin{tabular}{lccrrllll}
\hline \multicolumn{7}{c}{$95 \%$ CI } \\
Parameter & Exp. $(B)$ & Lower & Upper & p-value & Correlation structure & QIC & QICC \\
\hline Nocturnal headache & & & & & & & & \\
Lag_1 & $7.415 \mathrm{E}-51$ & $1.122 \mathrm{E}-100$ & 0.490 & 0.05 & Exchangeable & 921.611 & 913.392 \\
Lag_4 & $7.608 \mathrm{E}-38$ & $9.118 \mathrm{E}-73$ & 0.006 & 0.04 & Exchangeable & 921.819 & 914.458 \\
Lag_6 & $7.335 \mathrm{E}-40$ & $2.899 \mathrm{E}-82$ & $1,855.887$ & 0.07 & & & \\
Lag_6 & $1.032 \mathrm{E}-39$ & $9.147 \mathrm{E}-74$ & $1.165 \mathrm{E}-05$ & 0.03 & Exchangeable & 921.492 & 914.215 \\
Lag_2 (12-18 p.m.) & 5.184 & 3.441 & 7.809 & $<0.01$ & AR1 & 899.919 & 895.279
\end{tabular}

Note: Adjust by age, BMI, vision, anxiety, depression, PSQI, internet use, hand free use, brand device and SOP
Table V. Odds ratio (OR) of nocturnal headache and their $95 \%$ confidence intervals for lag dose adjusted for all other factors using GEE 
JHR

33,6

as 31 percent of children between the age of eight and ten own and use mobile phones[14]. A study in Korea in the year 2013 found the average age of children first owning and/or using mobile phone decreased from 12.5 years old in 2008 to 8.4 years old in 2011 . The results implied the tendency of children to own or use mobile phones at a younger age[14].

Internet use is a risk factor for nocturnal headaches $\left(\mathrm{OR}_{\mathrm{adj}} 2.14 ; 95 \% \mathrm{CI}: 1.07-4.25\right)$. Talking on smartphones in both internet and cellular modes often involves holding the device close to the head, and the electromagnetic radiation from smartphone to which the users are exposed induces a change in biological reaction including a change of protein in the brain and causes nervous system problems, especially headache symptoms[15]. Electromagnetic radiation from talking mode is nine times more intense than the standby mode[16]. A recent study has found a higher mean of radiated power during voice over internet protocol, which has been assessed at $1.9 \mathrm{~mW}$, than the mean of radiated power during voice over circuit switch calls, which has been assessed at $0.55 \mathrm{~mW}[17]$. The results indicate that talking on smartphones without hands-free devices can give rise to a headache.

The brand of the device has appeared to have a bearing on the nocturnal headache. From the analysis of smartphone use during night time, it was found among late night users that students using device brands other than Apple, most (83.6 percent) used SOP in the $\geqslant 2.00 \times 10^{-5} \mathrm{~mW}$ range, compared to the 58.9 percent figure of Apple brand device users. The result implies that users of smartphones other than Apple brand use the device heavily at night, thus contributing to the link between the device brand and nocturnal headache. It is important to note that device brand is a representative of areas where the device is used, and the device brand used popularly in rural areas, which has less density of the base station, will have an effect on sleep quality. The theory is in line with the findings from previous studies that the factors governing SOP include the control system of the operator's network, the wave frequency, the strength of the signal which depends on the signal density of the base station, the distance of the mobile phone from the base station and population density[18, 19].

The SOP, which was measured and stored in the device, can be viewed with the use of an application. SOP values in this study are thus lower than the values of smartphone electromagnetic radiation in other studies which used the external metering device and might be affected upward by the radiation from other sources. This value concurred with the average power consumption of a human cell, at $1 \times 10^{-9} \mathrm{~mW}[20]$. In this study, the maximum SOP was $1.55 \mathrm{~mW}$ which occurs during night time. Previous studies indicated most teenagers (62-72 percent) used advanced smartphones in the evening and at night, after 9.00 p.m., and during midnight to 3.00 a.m., with 34-55 percent of the use for texting and social media, and 24 percent for playing games[21].

The use of SOP in the morning (6:00-12:00 a.m.) and at night (00:00-6:00 a.m.) in the form of high power effect $\left(\geqslant 2.00 \times 10^{-5} \mathrm{~mW}\right)$ was found to link with morning headache and indicates that students with a morning headache will include those who use a smartphone heavily after midnight. Severe morning headache is not only the consequence of exposure to high doses of SOP but also due to sleep deprivation. Meanwhile, the use of SOP during the day time and in the morning $\left(\leqslant 1.79 \times 10^{-5}\right.$ and $1.80-1.99 \times 10^{-5} \mathrm{~mW}$, respectively) in the form of power effect has been found to induce a daytime headache. Furthermore, the use of a daily dose of SOP for six days apparently caused daytime headache in the form of a dose-response. The use of SOP in the evening $\left(\leqslant 1.79 \times 10^{-5}\right.$ and $\left.\geqslant 2.00 \times 10^{-5} \mathrm{~mW}\right)$ has been associated with an evening headache. Moreover, the exposure to daytime SOP for $6 \mathrm{~h}$ $\left(\leqslant 1.79 \times 10^{-5}\right.$ and $\left.\geqslant 2.00 \times 10^{-5} \mathrm{~mW}\right)$ in the form of power effect and a daily dose of SOP for five days has given rise to an evening headache in the form of a dose-response. The researcher has observed that SOP in $\leqslant 1.79 \times 10^{-5} \mathrm{~mW}$ range, which is the lowest level that can trigger a headache, still has a strong effect probably due to the sensitivity of each individual or the response of the nervous system to the frequency of smartphone electromagnetic radiation in this range. 
The nocturnal headache in the present study is different from the hypnic headache as it does not wake one up from sleep but it only occurs at night and has been found in only 5.3 percent of the participants. From the study on headache in different periods of the day, a nocturnal headache, mostly, can be classified as a migraine type, i.e. 12.2 percent (Table VI). The researcher has found that nocturnal headache is not a response to SOP during the evening, before bedtime. The finding indicates that using a smartphone before going to bed does not stimulate the brain, to result in a nocturnal headache. Meanwhile, daytime smartphone use with SOP at $1.80-1.99 \times 10^{-5} \mathrm{~mW}$ range and perhaps in combination with night time smartphone use can bring about a nocturnal headache. Furthermore, using a daily dose of SOP for seven days or delayed effect has been found to have nocturnal headache consequence in a reverse dose-response form, which is likely to be the adaptive process of the nervous system, particularly in a migraine type headache. The results from one study showed other kinds of protective response, for example, photophobia[22]. The researchers' findings ensure that both migraine and nocturnal headache will have specific responses to SOP. Noseda et al. found that light stimulations activated migraine by dura sensitive thalamic neurons that receive photic signals from the retinal ganglion cells and transmit signals to cortical areas and nociceptive. The retino-thalamic-cortical pathway provided exacerbation of migraine headache by light[23-25]. The light of smartphone displays is light-emitting diodes (LED) for backlit screens. These screens are lit in the back by short wavelength LEDs (460 $\mathrm{nm}$ )[26] that are sensitive to photoreceptors and can stimulate the retino-thalamic-cortical pathway. The information ensures that nocturnal headache in the study has been activated by output power and the light from smartphones.

Measuring smartphone's output power by using the data in the smartphone, not measuring from outside, can lead to misclassification of exposure. This study was a panel study, meaning the outcomes and exposures have been followed in the same sample groups which have been considered as controlling individual and environmental confounders. The tool of this study relied on the technology by creating a smartphone application which used recorded data every day and avoided recall bias. Finally, this study had a large sample size which can make even an analysis of the effect of slight SOP on the nervous system possible.

\section{Conclusion}

SOP, which is smartphone electromagnetic radiation, had a non-linear correlation with headaches during different periods of the day. Nocturnal headaches have been found to respond to the delayed effect of the daily dose of SOP in the form of a reverse dose-response, just like migraine headaches which have some other kinds of protective response, for example, photophobia. The information ensures that the nocturnal headache in this study is a migraine which has been activated by output power and the light from smartphones. Finally, for younger students, internet use has been a risk factor of the nocturnal headache. It is recommended that a limited time for smartphone use and delaying the use of smartphones to older age groups should be implemented in order to prevent migraine attacks at night.

\begin{tabular}{lcccrrr}
\hline & & Headache type & & \\
Time cycle headache & Migraine $n(\%)$ & TTH $n(\%)$ & Undetermined $n(\%)$ & Total $n(\%)$ & \\
\cline { 1 - 4 } Morning headache & $61(11.2)$ & $382(69.8)$ & $104(19.0)$ & $547(32.1)$ & Table VI. \\
Daytime headache & $60(11.7)$ & $360(69.9)$ & $95(18.4)$ & $515(30.2)$ & Time cycles headache \\
Evening headache & $21(3.8)$ & $460(83.2)$ & $72(13.0)$ & $553(32.4)$ & classified by \\
Nocturnal headache & $11(12.2)$ & $62(68.9)$ & $17(18.9)$ & $90(5.3)$ & headache type \\
\hline
\end{tabular}

\section{Adolescent smart phone users}


JHR

33,6

476

\section{References}

1. Pankaj BK. Primary nocturnal headache. Ann Neurosci. 2009; 16(1): 37-9.

2. Lin YK, Lin GY, Lee JT, Lee MS, Tsai CK, Hsu YW, et al. Associations between sleep quality and migraine frequency a cross-sectional case-control study. Medicine (Baltimore). 2016 Apr; 95(17): $1-7$.

3. Lucchesi LM1, Speciali JG, Santos-Silva R, Taddei JA, Tufik S, Bittencourt LR. Nocturnal awakening with headache and its relationship with sleep disorders in a population-based sample of adult inhabitants of São Paulo City, Brazil. Cephalalgia. 2010; 30(12): 1477-85.

4. Tarokha L, Jared M, Saletinc JM, Carskadonc MA. Sleep in adolescence: physiology, cognition and mental health. Neurosci Biobehav Rev. 2016; 70: 182-8.

5. Electronic Transactions Development Agency. Thailand internet user profile 2013. Bangkok: Electronic Transistors Development Agency; 2013.

6. Lu Y, Huang Y. Biological effects of mobile phone radiation, IEEE International Conference on Microwave and Millimeter Wave Technology (ICMMT), Shenzhen, China, May 5-8. 2012; 2, doi: 10.1109/ICMMT.2012.6230101

7. Kumar P, Dongre K, Ghail G. Prevalence of subjective symptoms in mobile users aged more than 18 years in Nagpur. Indian J Physiother Occup Ther. 2013; 7(2): 260-4.

8. Schoeni A, Roser K, Röösli M. Symptoms and cognitive functions in adolescents in relation to mobile phone use during night. PLOS One. 2015; 10(7): 1-15.

9. Nathan N, Zeitzer J. A survey study of the association between mobile phone use and daytime sleepiness in California high school students. BMC Public Health. 2013; 13(840): 1-5.

10. Boulloche N, Denuelle M, Payoux P, Fabre N, Trotter Y, Geraud G. Photophobia in migraine: a PET study of visual cortex hyperexcitability and its modulation by pain. JNNP. 2010; 81(9): 974-84.

11. Ali EN. Excitability and photosensitivity in neurological disorders using pupsillary response to sparse multifocal stimuli. Canberra: Australian National University; 2016.

12. Chu MK, Song HG, Kim C, Lee BC. Clinical features of headache associated with mobile phone use: a cross-sectional study in university students. BMC Neurol. 2011; 11(115): 1-7.

13. Rho Y-I, Chung H-J, Lee K-H, Eun B-L, Eun S-H, Nam S-O, et al. Prevalence and clinical characteristics of primary headachesamong school children in South Korea: a nationwide survey. Headache. 2012 Apr; 52(4): 592-9.

14. Byun YH, Ha M, Kwon HJ, Choi KH, Burm E, Choi Y, et al. Epidemiological characteristics of mobilephone ownership and use in Korean children and adolescents. Environ Health Toxicol. 2013 Dec; 28: 1-8.

15. Sudan M. Cell phone exposures and headaches, hearing loss, and behavioral problems in children. University of California; ProQuest 789 East Eisenhower Parkway. 2012.

16. Hunga C-S, Anderson C, Horne JA. Mobile phone 'talk-mode' signal delays EEG determined sleep onset. Neuroscience Letters. 2007; 421: 82-6.

17. Jovanovic D, Bragard G, Picard D, Chauvin S. Mobile telephones: a comparison of radiated power between 3G VoIP calls and 3G VoCS calls. J Expo Sci Environ Epidemiol. 2015; 25: 80-3.

18. Hillert L, Ahlbom A, Neasham D, Feychting M, Järup L, Navin R, et al. Call-related factors influencing output power from mobile phones. J Expo Sci Environ Epidemiol. 2006; 16(6): 507-14.

19. Kelsh MA, Shum M, Sheppard AR, McNeely M, Kuster N, Lau E, et al. Measured radiofrequency exposure during various mobile-phone use scenarios. J Expo Sci Environ Epidemiol. 2011; 21: $343-54$.

20. Wikipedia. Orders of magnitude (power). [cited 2018]. Available from: https://en.wikipedia.org/ wiki/Orders_of_magnitude_(power)

21. Bruni O, Sette S, Fontanesi L, Baiocco R, Laghi F, Baumgartner E. Technology use and sleep quality in preadolescence and adolescence. J Clin Sleep Med. 2015; 11(12): 1433-41. 
22. Borsook D, Maleki N, Becerra L, McEwen B. Understanding migraine through the lens of maladaptive stress responses: a model disease of allostatic load. Neuron. 2012; 73: 219-34.

23. Noseda R, Bernstein CA, Nir RR, Lee AJ, Fulton AB, Bertisch SM, et al. A retinal-thalamic pathway for photophobia during migraine. Cephalalgia. 2009; 29: 2-3.

Adolescent smart phone users

24. Noseda R, Burstein R. Migraine pathophysiology: anatomy of the trigeminovascular pathway and associated neurological symptoms, CSD, sensitization and modulation of pain. Pain. 2013; 154(1): 1-21.

25. Noseda R, Kainz V, Jakubowski M, Gooley JJ, Saper CB, Digre K, et al. A neural mechanism for exacerbation of headache by light. Nat Neurosci. 2010; 13(2): 239-45.

26. Münch M, Kobialka S, Steiner R, Oelhafen P, Wirz-Justice A, Cajochen C. Wavelength-dependent effects of evening light exposure on sleep architecture and sleep EEG power density in men. Am J Physiol Regul Integr Comp Physiol. 2006; 290: 1421-8.

\section{Corresponding author}

Phongtape Wiwatanadate can be contacted at: pwiwatanadate@gmail.com

For instructions on how to order reprints of this article, please visit our website: 